The Effectiveness of Antecedents Control and Differential Reinforcement of Alternative Behaviors in Reducing Screen Time on an Adolescent with Autism Spectrum Disorder: A Single-case Design

Elisabeth Santoso ${ }^{a}$ and Mayke Sugianto Tedjasaputra ${ }^{b^{*}}$

${ }^{a}$ Faculty of Psychology, Universitas Indonesia, Depok, Indonesia; Department of Developmental Psychology, Faculty of Psychology, Universitas Indonesia, Depok, Indonesia

*Corresponding author:

Mayke Sugianto Tedjasaputra

Department of Developmental Psychology

Faculty of Psychology, Universitas Indonesia

Jl. Lkr. Kampus Raya, Depok,

Jawa Barat Indonesia, 16424

Tel.: +62 217270004

Email address: maykeui@gmail.com 


\title{
The Effectiveness of Antecedents Control and Differential Reinforcement of Alternative Behaviors in Reducing Screen Time on an Adolescent with Autism Spectrum Disorder: A Single-case Design
}

\begin{abstract}
Studies on normal children's and adolescents' use of intervention techniques to reduce screen media usage have recently gained much attention. However, studies on screen time reduction intervention in children with developmental disorders, including autism spectrum disorder (ASD), have been scarce. Compared to the typical population, children with ASD spend more time on screen media and are thus at greater risk of its physical and psychological consequences. This paper aimed to investigate the effectiveness of behavior modification techniques, specifically antecedent control and differential reinforcement of alternative behaviors (DRA), in reducing screen time for an adolescent male aged 12 years and 9 months with mild ASD. Previous research on normally developed children showed inconsistent results on the application of these techniques. In this study, technique effectiveness was evaluated by collecting and comparing pretreatment and post-treatment data. The results showed that both techniques could reduce participants' screen time duration by $55 \%$.
\end{abstract}

Keywords: antecedents' control, differential reinforcement of alternative behaviors (DRA), autism spectrum disorder

\section{Introduction}

Interest on the influence of screen media usage on children's and adolescents' lifestyle has increased during the last decade with the discovery of its potential health consequences (PeiroVelert et al., 2014). Several studies involving normally developed children found a correlation between screen time duration and social skills, including socioemotional competence in early childhood (Intusoma et al., 2013); eye contact (Heffler \& Oestreicher, 2016); and social interest (American Academy of Pediatrics, 2016). Excessive screen time on children is associated with withdrawal from real-life social contact (Bickham \& Rich, 2006), multiple risk behaviors (Carson et al., 2011), and speech delay (Chonchaiya \& Pruksananonda, 2008). Other studies found health risks regarding screen media usage, including higher risk of obesity (MartinezGomez et al., 2010), depression, and anxiety (Cao et al., 2011).

Because of the potential health, psychological, and social risks of excessive screen time, the American Academy of Pediatrics (2016) proposed no more than two hours of screen time per day for children. However, increased access to technology and gadgets have made it difficult to control children's screen time. The first exposure occurs at a much younger age (Hermawati et al., 2018). Hermawati also stated that parents actively encourage children to use electronic media for entertainment to keep them occupied so that parents can freely work on their own.

While some studies have investigated the effectiveness of screen time reduction intervention in children and adolescents with typical development (Wahi et al., 2011; Friedrich et al., 2014), similar studies are less common on children with ASD. ASD is a neurodevelopmental disorder characterized by difficulties with reciprocal social interaction and frequent presentation of 
restricted and repetitive behavior (APA, 2013). Children with ASD face challenges regarding basic social interaction skills such as language acquisition (Spears, 2010) and joint attention (Dawson et al., 2004). Compared to normal children, children with ASD spend more time on sedentary activities, including screen time. They are also at greater risk of obesity and social disengagement (McCoy et al., 2016; Jones et al., 2017; Flom \& Johnson, 2010). Given the potential consequences of excessive screen media usage on social skills and the nature of ASD, which inhibits children in acquiring such skills, interventions that can help reduce or limit their screen time are urgently needed.

Some previous studies found a relation among antecedent control, reinforcement, and screen time limitation (Carlson et al., 2010; Maitland et al., 2013), but longitudinal research is limited with regard to their causal relation (Carlson et al., 2010). Prior research on screen time reduction intervention mostly used monitoring, counseling, and providing health curricula (Wahi et al.,2011; Ghassemi \& Granger, 2012; Schmidt et al., 2012; Wu et al., 2016). In addition, studies that applied antecedent control by providing alternative activities to replace screen time have shown inconsistent results (Salmon et al., 2010; Wu et al., 2016).

The study discussed in this paper aimed to investigate the effectiveness of behavior modification techniques, specifically antecedent control and DRA, in reducing screen time. We hypothesized that both techniques can reduce screen time duration in this study's participant. This participant is an adolescent male aged 12 years and 9 months, diagnosed with mild ASD, and with language impairment. Before receiving treatment, his average screen time in a typical day is seven hours and seven minutes (excluding screen time on holidays). This study aims to reduce his screen time duration to two hours per day based on the screen time limit recommendation by the American Academy of Pediatrics.

\section{Method}

This is a single-subject design, a study involving only one participant, to test causal relations between variables (Gravetter \& Forzano, 2012). The participant of this study is an adolescent male aged 12 years and 9 months. Two months before the study, he was diagnosed with mild ASD based on a comprehensive psychological assessment by this study's researchers. The subject's mother was involved in this study. She was asked to record the subject's screen time every day on a Screen Time Observation Form, which was constructed by the first researcher to help monitor screen time activities. This was the only instrument used in the study.

The program was preceded by a comprehensive assessment of problem behavior, which adopted the functional behavioral analysis (FBA) model. This assessment was conducted to evaluate the antecedent and consequence of problem behavior before the subject received any treatment. Table I below shows the FBA results. 
Table I. Functional Behavioral Analysis Results

\begin{tabular}{|c|c|c|}
\hline Antecedent & Behavior & Consequence \\
\hline $\begin{array}{l}\text { Unlimited screen time facilities: } \\
\text { Nonstop Wi-Fi connection } \\
\text { Gadgets and TV }\end{array}$ & $\begin{array}{lr}\text { Streams and plays } \\
\text { gadgets }\end{array}$ & Parents permit the behavior and \\
\hline $\begin{array}{l}\text { Free time from waking up (05.30) } \\
\text { and after school until bedtime } \\
(14.00-00.00)\end{array}$ & $\begin{array}{l}\text { only stopping to take a } \\
\text { bath and sleep. }\end{array}$ & time activities. \\
\hline
\end{tabular}

The antecedents of the problem behavior were the unlimited screen time facilities and the lack of house rules. His parents' consent and ignorance regarding his screen time activities reinforced the target behavior, which was a consequence. This antecedent behavior-consequence pattern had persisted for 12 years (since he was six months old). We assume that the antecedent and consequence need to be modified to elicit the desired behavior.

Antecedent control and DRA were applied in this study. In the former procedure, antecedents were manipulated technically by presenting $S^{D}$ (stimulus discriminant) to produce desired behaviors (Miltenberger, 2012). In this study, the technique involved presenting $S^{\mathrm{D}}$ in the form of strictly scheduled off-screen activities as an alternative to screen time activities. We integrated social play, art, and domestic activities in his daily schedule to replace screen time. If the subject engaged in alternative activities as scheduled instead of screen time activities, he was given positive reinforcement, including social and consumable reinforcement. These comprise the DRA technique (Miltenberger, 2012).

This study was divided into three phases: baseline, treatment, and post-treatment. Before the baseline phase, informed consent was provided by the subject's mother, as the subject was unable to do so because of his minimal understanding of verbal cues. The baseline phase lasted six days. The mother recorded the subject's screen time duration every day, supervised by a researcher, before any treatment was given. The treatment phase lasted 20 days with gradually increasing off-screen activities and gradually decreasing screen time activities.

The intervention design described above is presented in Table II.

Table II. Intervention Design

\begin{tabular}{ll}
\hline \multicolumn{1}{c}{ Schedule } & \multicolumn{1}{c}{ Activities } \\
\hline July 9, 2018 & Initial assessment and informed consent. \\
\hline July 16-20, 2018 & $\begin{array}{l}\text { Baseline: recording subject's screen time } \\
\text { before any intervention. }\end{array}$ \\
\hline \multirow{2}{*}{$\begin{array}{l}\text { July 30-August 3, }, \\
\text { First week of intervention: reducing screen } \\
\text { time to five hours per day. }\end{array}$} & $\begin{array}{l}\text { Alternative activities: play and domestic } \\
\text { activities. }\end{array}$ \\
\hline $\begin{array}{l}\text { Reinforcement: social and consumable } \\
\text { reinforcement. }\end{array}$ \\
\hline August 6-10, 2018 & $\begin{array}{l}\text { Second week of intervention: reducing screen } \\
\text { time to four hours per day. }\end{array}$ \\
\hline
\end{tabular}




\begin{tabular}{|c|c|}
\hline & $\begin{array}{l}\text { Alternative activities: play and domestic } \\
\text { activities. }\end{array}$ \\
\hline & $\begin{array}{l}\text { Reinforcement: social, consumable, and } \\
\text { activity reinforcement. }\end{array}$ \\
\hline \multirow{3}{*}{ August 13-17, 2018} & $\begin{array}{l}\text { Third week of intervention: reducing screen } \\
\text { time to three hours per day. }\end{array}$ \\
\hline & $\begin{array}{l}\text { Alternative activities: play, art, and domestic } \\
\text { activities. }\end{array}$ \\
\hline & $\begin{array}{l}\text { Reinforcement: social, consumable, and } \\
\text { activity reinforcement. }\end{array}$ \\
\hline \multirow{3}{*}{ August $20-24,2018$} & $\begin{array}{l}\text { Fourth week of intervention: reducing screen } \\
\text { time to two hours per day. }\end{array}$ \\
\hline & $\begin{array}{l}\text { Alternative activities: play, art, and domestic } \\
\text { activities. }\end{array}$ \\
\hline & $\begin{array}{l}\text { Reinforcement: social and activity } \\
\text { reinforcement. }\end{array}$ \\
\hline August $27-31,2018$ & $\begin{array}{l}\text { Post-test: recording subject's screen time } \\
\text { after intervention. }\end{array}$ \\
\hline
\end{tabular}

We conducted no statistical analysis in this study and instead used descriptive analysis to evaluate the effectiveness of intervention. Screen time data before (pre-) and after (post-) treatment were collected, compared, and analyzed.

\section{Results}

The baseline phase was conducted for six days. We asked the participant's mother to record his screen time duration from waking up (0600) and after school until bedtime (0000). His screen time duration was only recorded during school days and not holidays (Saturday or Sunday) to prevent any fluctuation caused by different amounts of available leisure time to use gadgets. The intervention was conducted for 20 days. During this phase, we created a schedule that contained off-screen activities. The participant was encouraged to follow the schedule with direct supervision from a researcher from 3:00 p.m. to 5:00 p.m. and from his mother afterward. Off-screen activities were gradually increased by one hour per week to allow the participant to adapt to the new schedule.

The subject received positive reinforcement, such as social reinforcement (expressions of appreciation, hugs, pats on the head, and thumbs up from researcher/parents), consumable reinforcement (his favorite food/snack), and activities that were pleasurable for him (taking public transportation, going swimming, etc.). These rewards were discussed with the mother during the initial assessment. Consumable reinforcement was retracted on the fourth week to generalize the desired behavior without the presentation of his favorite foods. The post-test was conducted two days after the intervention phase. During five days of the post-test phase, the mother was asked to record the participant's screen time duration when he was no longer getting any treatment. Figure 1 below shows the subject's screen time duration (in minutes) during the baseline, intervention, and postintervention phases. 


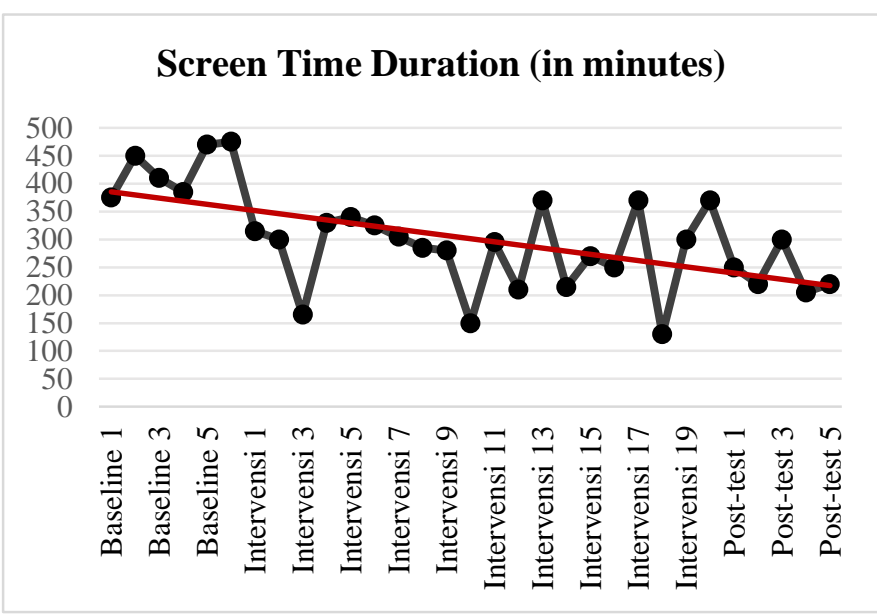

Fig. 1. Screen Time Duration (in Minutes) During Baseline, Intervention, and Postintervention

Despite fluctuations in the participant's screen time duration in all three phases, a trend emerged that showed both treatments had successfully reduced his screen time. During the baseline phase, the subject used screen media devices for 7 hours and 7 minutes per day on average. During the intervention stage, this was reduced to 4 hours and 38 minutes per day. During the post-test phase, the average screen time duration was further reduced to 3 hours and 59 minutes. These data showed an average screen time reduction of 3 hours and 59 minutes, a 55\% improvement.

However, since our initial target was to reduce the subject's screen time duration to two hours per day following the recommendation by the American Academy of Pediatrics (2016), this study's results fell short.

\section{Discussion}

The nature of antecedent control, which technically manipulates the environment to decrease adaptive behaviors and prevent problem behaviors, is effective for this subject. We believe this was because the stimulus discriminant $\left(S^{D}\right)$ was never presented or established to the child before treatment. This finding is supported by previous studies that found an association between consistent limitation and rules from parents and screen time limits in children (Carlson et al., 2010; Minges et al., 2015). The antecedent control procedure is necessary when the absence of $S^{\mathrm{D}}$ allows a problem behavior to manifest (Miltenberger, 2012). In this case, setting a consistent limitation and direct supervision for 20 days worked particularly when such rules were not applied previously.

Meta-analysis studies from Wahi et al. (2011) and Friedrich et al. (2014) found reductions in screen time following the enhancement of physical activities. In other words, screen time can be minimized when children have alternative leisure activities. Research by Eipstein et al. (1997) found that positive reinforcement following sedentary behavior reduction increases the odds of doing alternative activities. This finding supported the hypothesis that DRA can increase the likelihood of engaging in these alternative behaviors. 
However, this study failed to meet its initial target. The fluctuating nature of his screen time graph means the result of this program is still inconsistent, and this may be attributed to several factors. Some studies tried to analyze environmental factors that encourage excessive screen media usage in children. Crawford et al. (2010) and Wilson et al. (2015) found that families' sedentary and physical activities influence children's preferred activities. Children with parents who spend much of their time doing sedentary activities have been found to enjoy the same activities. Similarly, Hume et al. (2010) found a positive correlation between the electronic media usage of parents and that of children.

In our case, this participant's parents also have excessive sedentary activities. His family members' leisure time is spent gathered in front of the television or playing gadgets together. His parents admitted that they do not enjoy physical and interactive activities. On the 3rd, 10th, and 18th day of intervention, the subject successfully reduced his screen time to less than three hours per day. This was because parents took him to outdoor activities such as swimming, shopping at the supermarket, or short trips. On the 13th, 17th, and 20th day of intervention and the 3rd day of post-test, the subject's screen time increased to more than six hours per day, which was because his mother was not at home in the evening and was therefore unable to supervise his activities.

Another inhibiting factor is parental perception of screen time activities. Minges et al. (2015) conducted structured interviews with parents and teens to find out their perceptions of screen time. The study found that in this millennial era, parents and teens consider screen time as an integral part of their daily life. Apparently, the researchers also found that such a point of view distracted parents from knowing more about screen time consequences. A similar study by Thompson et al. (2017) found that parents see gadget use as something that fosters closeness in the family; hence, they encourage their children to use gadgets. This becomes problematic, however, when parents encounter conflict when limiting screen time.

Similarly, the subject's parents also admitted that they allow their son to play gadgets so that he can learn language. Despite the lack of significant change in his language acquisition during his excessive screen time, the parents' perception was unchanged. We assume that such perception distracted his parents from consistently implementing the program.

Another factor that needs consideration is the subject's home physical environment. Media equipment in the home - and, to a lesser extent, the bedroom - is positively associated with children's sedentary behavior (Maitland et al., 2013). Unfortunately, gadgets are accessible in this participant's house. There are televisions in the living room and in each bedroom. Every family member in the house has their own gadgets, such as tablets and smartphones. We found it quite difficult to control the participant's screen media usage when all facilities are accessible and especially when other family members are also using them excessively.

These inhibiting factors also serve as insights for future research. We suggest that future studies comprehensively assess parents' preferred activities and perception of screen time activities before implementing any program. Future research also needs to investigate the effectiveness 
of antecedent control by steering family members' activities and home physical environment toward reducing screen time. Parents should also receive psychoeducation and training to enhance their knowledge of the consequences of excessive screen time. We also suggest that future research involve more participants for better generalization.

\section{Conclusion}

In this study, antecedent control procedure and DRA successfully reduced the subject's screen time duration by 55\%. However, it failed to meet the two-hour daily screen time limit as recommended by the American Academy Pediatrics (2016). Thus, when conducted for 20 days, both techniques are not necessarily effective in reducing screen time to the recommended levels.

This study has several limitations. We did not test the instrument used in this study for validity and reliability; we suggest that future researchers do so before replicating the study. Interrater agreement during screen time recording should be considered as well. Another limitation is the short study period; we believe that lengthening the study period by adding more intervention days can provide more conclusive results.

\section{References}

American Academy of Pediatrics. (2016). Media use in school-aged children and adolescents: Policy statement. Pediatrics, 138(5), 1-8. DOI: 10.1542/peds.2016-2592.

American Psychiatric Association (APA). (2013). Diagnostic and Statistical Manual of Mental Disorders, ( $^{\text {th }}$ ed.). Washington: American Psychiatric Publishing.

Bickham, D. S., \& Rich, M. (2006). Is television viewing associated with social isolation? Roles of exposure time, viewing context, and violent content. Archives of Pediatrics and Adolescents Medicine, 160(4), 387-392.

Cao, H., Qian, Q., Weng, T., Yuan, C., Sun, Y., Wang, H., \& Tao, F. (2011). Screen time, physical activity and mental health among urban adolescents in China. Preventive Medicine, 53, 316-320. DOI: 10.1016/j.ypmed.2011.09.002.

Carlson, S. A., Fulton, J. E., Lee, S. M., Foley, J. T., Heizler, C., \& Huhman, M. (2010). Influence of limit-setting and participation in physical activity on youth screen time. The American Academy of Pediatrics, 126(1), 89-99. DOI: 10.1542/peds.2009-3374.

Carson, V., Pickett, W., \& Janssen, I. (2011). Screen time and risk behaviors in 10- to 16-year-old Canadian youth. Preventive Medicine, 52(2), 99-103. DOI: 10.1016/j.ypmed.2010.07.005.

Chonchaiya, W., \& Pruksananonda, C. (2008). Television viewing associates with delayed language development. Acta Paediatricia, 97(7), 997-982. DOI: 10.1111/j.1651-2227.2008.00831.x.

Crawford, D., Cleland, V., Timperio, A., Salmon, J., Andrianopoulos, N., Roberts, R., Giles-Corti, B., Baur, L., $\&$ Ball, K. (2010). The longitudinal influence of home and neighborhood environments on children's body mass index and physical activity over 5 years: The CLAN study. International Journal of Obesity, 34(7), 1177-1187. DOI: 10.1038/ijo.2010.57.

Dawson, G., Toth, K., Abbott, R., Osterling, J., Munson, J., Estes, A., \& Liaw, J. (2004). Early social attention impairments in autism: Social orienting, joing attention, and attention to distress. Developmental Psychology, 40(2), 271-283.

Eipstein, L. H., Saelens, B. E., Myers, M. D., \& Dominica, V. (1997). Effects of decreasing sedentary behaviors on activity choice in obese children. Health Psychology, 16(2), 107-113.

Flom, R., \& Johnson, S. (2010). The effects of adults' affective expression and direction of visual gaze on 12 month-olds' visual preferences following a 5 minute, 1-day, or 1-month delay. British Journal of Developmental Psychology, 29, 64-85. 
Friedrich, R. R., Pinto Polet, J., Schuch, I., \& Wagner, M. B. (2014). Effect of intervention programs in schools to reduce screen time: A meta-analysis. Journal de Pediatria, 90(3), 232-241. DOI: 10.1016/j.jped.2014.01.003.

Ghassemi, M., \& Granger, C. (2012). Effectiveness of interventions for reducing screen time in children: Rapid review of the evidence. Chronic Disease and Injury Prevention, Region of Peel Public Health, issued in October 2012.

Graveter, F. J., \& Forzano, L. B. (2012). Research Methods for The Behavioral Sciences (4 ${ }^{\text {th }}$ ed.). Wadsworth: Cengage Learning.

Heffler, K. F., \& Oestreicher, L. M. (2016). Causation model of autism: Audiovisual brain specialization in infancy competes with social brain networks. Medical Hypotheses, 91, 114-122. DOI: 10.1016/j.mehy.2015.06.019.

Hermawati, D., Rahmadi, F. A., Sumekar, T. A., \& Winarni, T. I. (2018). Early electronic screen exposure and autistic-like symptoms. Intractable and Rare Diseases Research, 1-3. DOI: 10.5582/irdr.2018.01007.

Hume, C., Van der Horst, K., Brug, J., Salmon, J., \& Oenema, A. (2010). Understanding the correlates of adolescents' TV viewing: A social ecological approach. International Journal of Pediatric Obesity, 5(2), 161-168. DOI: 10.3109/17477160903242550.

Intusoma, U., Mo-suwan, L., Ruangdaraganon, N., Panyayong, B., \& Chongsuvivatwong, V. (2013). Effect on television viewing on social-emotional competence of young Thai children. Infant Behavior and Development, 36, 679-685. DOI: 10.1016/j.infbeh.2013.07.001.

Jones, R. A., Downing, J., Rinehart, N. J., Barnett, L. M., May, T., McGillivray, J. A., Papadopoulos, N. V., Skouteris, H., Timperio, A., \& Hinkley, T. (2017). Physical activity, sedentary behavior and their correlates in children with Autism Spectrum Disorder: A systematic review. PLoS ONE, 12(2), 1-23. DOI: 10.1371/journal.pone.0172482.

Maitland, C., Stratton, G., Foster, S., Braham, R., \& Rosenberg, M. (2013). A place for play? The influence of the home physical environment on children's physical activity and sedentary behavior. International Journal of Behavioral Nutrition and Physical Activity, 10(99), 1-21.

Martinez-Gomez, D., Rey-Lopez, J. P., Chillom P., Gomez-Martinez, S., Vincente-Rodriguez, G., MartinMatillas, M., Garcia-Fuentes, M., Delgado, M., Moreno, L. A., Veiga, O. L., Eisenmann, J. C., Marcos, A., \& AVENA Study Group. (2010). Excessive TV viewing and cardiovascular disease risk factors in adolescents: The AVENA cross-sectional study. BMC Public Health, 10(274). DOI: 10.1186/1471-245810-274.

McCoy, S. M., Jakicic, J. M., \& Gibbs, B. B. (2016). Comparison of obesity, physical activity, and sedentary behaviors between adolescents with autism spectrum disorder and without. Journal of Autism and Developmental Disorder, 46(7), 2317-2326. DOI: 10.1007/s10803-016-2762-0.

Miltenberger, R. G. (2012). Behavior Modification: Principles and Procedures (5 $5^{\text {th }}$ ed.). Wadsworth: Cengage Learning.

Minges, K. E., Salmon, J., Dunstan, D. W., Owen, N., Chao, A., \& Whittemore, R. (2015). Reducing youth screen time: Qualitative metasynthesis of findings on barriers and facilitators. Health Psychology, 34(4), 381-397. DOI: $10.1037 /$ hea0000172.

Peiro-Velert. C., Valencia-Peris, A., Gonzalez, L. M., Garcia-Masso, X., Serra-Ano, P., \& Devis-Devis, J. (2014). Screen media usage, scleep time and academic performance in Adolescents: Clustering a self-organizing maps analysis. Plos One, 9(6), 1-9. DOI: 10.1371/journal.pone.0099478.

Salmon, J., Jorna, M., Hume, C., Arundell, L., Chahine, N., Tienstra, M., \& Crawford, D. (2010). A translational research intervention to reduce screen behaviours and promote physical activity among children: Switch2-activity. Health Promotion International, 26(3), 311-321. DOI: 10.1093/heapro/daq078.

Schmidt, M. E., Haines, J., O’Brien, A., McDonald, J., Price, S., Sherry, B., \& Taveras, E. M. (2012). Systematic review of effective strategies for reducing screen time among young children. Pediatric Obesity, 20(7), 1338-1354. DOI: 10.1038/oby.2011.348.

Spears, E. W. (2010). The Autism Book: What Every Parent Needs to Know About Early Detection, Treatment, Recovery, and Prevention. New York: Little, Brown and Company.

Thompson, J. L., Sebire, S. J., Kesten, J. M., Zahra, J., Edwards, M., Solomon-Moore, E., \& Jago, R. (2017). BMC Public Health, 17(471), 1-9. DOI: 10.1186/s.12889-017-4394-5. 
Wahi, G., Parkin, P. C., Beyene, J., Uleryk, E. M., \& Birken, C. S. (2011). Effectiveness of interventions aimed at reducing screen time in children: A systematic review and meta-analysis of randomized control trials. Archives of Pediatrics and Adolescent Medicine, 165(11), 979-986. DOI: 10.1001/archpediatrics.2011.122.

Wu, L., Sun, S., He, Y., \& Jiang, B. (2016). The effect of interventions targeting screen time reduction: A systematic review and meta-analysis. Medicine, 96(27), 1-8. DOI: 10.1097/MD.0000000000004029.

Wilson, K. S., Spink, K. S., \& Brawley, L. R. (2014). Physical activity lapses and parental social control: 'It's not such a bad thing'. Qualitative Research in Sport, Exercise and Health, 7(4), 429-448. DOI: 10.1080/2159676X.2014.949831. 